\title{
Connecting small-scale producers and consumers: Exploring the feasibility of online food hubs in low-income communities
}

\author{
Michelle L. Kaiser, ${ }^{a}{ }^{*}$ Kelsey Ryan-Simkins, ${ }^{\mathrm{b}}$ Julia Dionne, ${ }^{\mathrm{c}}$ and Erica K. Pence ${ }^{\mathrm{d}}$ \\ Ohio State University
}

Submitted April 26, 2019 / Revised September 25 and December 15, 2019 / Accepted December 16, 2019 /

Published online May 4, 2020

Citation: Kaiser, M. L., Ryan-Simkins, K., Dionne, J., \& Pence, E. K. (2020). Connecting small-scale producers and consumers: Exploring the feasibility of online food hubs in low-income communities. Journal of Agriculture, Food Systems, and Community Development, 9(3), 179-196. https://doi.org/10.5304/jafscd.2020.093.019

Copyright (C) 2020 by the Authors. Published by the Lyson Center for Civic Agriculture and Food Systems. Open access under CC-BY license.

\begin{abstract}
Sustainable agriculture and community food security (CFS) are frameworks commonly used, but often separately, within the broader alternative food movement. Sustainable agriculture is productioncentered, with a focus on environmental degradation and family farm viability, whereas CFS shifts research from household-level measures of food
\end{abstract}

\footnotetext{
a* Corresponding author: Michelle L. Kaiser, PhD, MSW, MPH, Associate Professor, College of Social Work, Ohio State University; 1947 North College, 325-V Stillman Hall; Columbus, OH 43210 USA; Kaiser.267@,osu.edu

b Kelsey Ryan-Simkins, MA, Doctoral Student, The Ohio State University; 2021 Coffey Road; Columbus, OH 43210 USA; ryan-simkins.1@,osu.edu

c Julia Dionne, BA, Dual Master of Public Administration/ Master of Public Health Student, The Ohio State University; 1800 Cannon Drive; Columbus, OH 43210 USA; dionne.8@osu.edu

d Erica K. Pence, MSW, Doctoral Student and Graduate Research Associate, College of Social Work, The Ohio State University; 1947 College Road North; Columbus, OH 43210 USA; pence.146@osu.edu
}

security to consider larger geographic areas in terms of equitable healthy food access and social justice. The challenge of both movements continues to be the intersection of these ideals to create a sustainable situation in which the needs of producers and consumers can be met simultaneously. We explored the underlying values of local, small-scale producers and consumers living within an impoverished neighborhood in Columbus, Ohio, a large Midwestern city, as they related to participation in an online food hub. Twenty-one consumers participated in three focus groups, and interviews were conducted with eight producers. Our interest was primarily in whether and how these articulated values fit into sustainable agriculture and CFS frame-

\section{Authors' Note Regarding Implications of COVID-19} Our research was conducted before the COVID-19 pandemic. An addendum on pages 14-15 provides relevant updates to the research as of late April 2020.

\section{Funding Disclosure}

This project was funded through an Ohio State University Initiative for Food and AgriCultural Transformation (InFACT) grant. 
works, and if there was any evidence of commonalities or intersections between producers and consumers in the context of these frameworks. We hypothesized that producers would be oriented toward the economic viability of their small-scale operations, while consumers would be oriented toward improved food access that was convenient and affordable. We identified three prominent themes from both the consumers' and producers' articulated values. We found that an online food hub appealed to some producers and consumers, but that the barriers identified were more prominent than the benefits, and the desire for the proposed online food hub was not sufficient to pursue moving forward with a full-scale version of an online food hub at the time.

\section{Keywords}

Community Food Security, Sustainable Agriculture, Alternative Food Network, Food Access, Local Food, Online Food Hub, Low-Income Community

\section{Introduction}

Over the past three decades, academics, practitioners, and activists have brought the ideals and language of sustainable agriculture and food security into the U.S. vernacular through research (e.g., see Alaimo, Briefel, Frongillo, \& Olson, 1998), federally funded projects (e.g., Sustainable Agriculture Research and Education, 2012; U.S. Department of Agriculture [USDA] National Institute of Food and Agriculture [NIFA], 2017, 2018), Farm Bill policies (e.g., Agriculture Act of 2014), and higher education programs (USDA National Agricultural Library, n.d.).

Allen's (2004) seminal "alternative food and agriculture" research frames sustainable agriculture as more "production-centered," and focused on issues like "environmental degradation and the viability of the family farm," while community food security (CFS) primarily is oriented toward "distribution and consumption, such as food access and nutrition" concerns (p. 2). These approaches are often referred to as alternative food networks (AFNs) (Sarmiento, 2017). AFNs emphasize access to fresh, unprocessed foods grown in or near the community in which they are sold and aim to provide direct-to-consumer engagement between pro- ducers and consumers (Bruce \& Som Castellano, 2017). Farmers markets, community supported agriculture (CSA), mobile food markets, food hubs, and urban farms are examples of AFNs.

The present research is part of a broader feasibility study for an online food hub in a low-income, low-food access neighborhood in Columbus, Ohio, that was conducted by a private theological school, a public land-grant institution, an institutional farm, and a nonprofit inner-city urban farm. Food hubs, one type of AFN, can take various forms. They are spaces, physical or virtual, that strategically coordinate (Berti \& Mulligan, 2016) aggregation, distribution, and marketing of local food for producers to expand their market (Levkoe et al., 2018). We were interested in exploring the underlying values of producers and consumers as they relate to participation in an online food hub. Furthermore, our interest was primarily in whether and how these articulated values fit into sustainable agriculture and CFS frameworks, and if there was any evidence of commonalities or intersections between producers and consumers in the context of these frameworks. We hypothesized that producers would be oriented toward sustainable agriculture, specifically in terms of the viability of their small-scale operations, with some level of interest in improving food access. We hypothesized that consumers who were residents of the low-income, low-access neighborhood would be oriented toward improving food access through convenience and appropriate pricing.

\section{Literature Review}

A prolific, multidisciplinary body of research about food security exists, while CFS research is less predominant. Among these, annual USDA Economic Research Service [ERS] U.S. food security reports (e.g., Coleman-Jensen, Rabbitt, Gregory, \& Singh, 2018), Feeding America's accessible Map the Meal Gap research and hunger reports (e.g., Gundersen et al., 2017; Weinfeld et al., 2014), and Ver Ploeg et al.'s (2009) report to Congress about food deserts have brought attention to issues that exemplify historical and contemporary interconnected economic, racial, and geographic disparities. These are also evident in an abundance of peer-reviewed literature related to food access (e.g., Larson, Story, 
\& Nelson, 2009; Raja, Ma, \& Yadav, 2008; Zenk et al., 2005), food insecurity and poverty (e.g., Cook \& Frank, 2008), and physical and mental health consequences (e.g., see Casey et al., 2004; Gundersen \& Ziliak, 2015; Martin, Maddocks, Chen, Gilman, \& Colman, 2016; Olson, 1999). CFS shifts research from household-level measures rooted in economic, racial, and social characteristics with dietary and health outcomes to research that is intended to consider larger geographic areas in terms of social justice, equitable healthy food access, community self-reliance, culture, environmental sustainability, and public health (Hamm \& Bellows, 2003; Pothukuchi, Joseph, Burton, \& Fisher, 2002; Winne, 2004). CFS activities are similar to AFNs and include CSAs, farmers markets, community gardens, farm-to-institution programs, community food assessments, food policy councils, community development, and planning programs (Community Food Security Coalition, n.d.).

Sustainability values relate to creating and maintaining balanced eco-social systems that promote equity across communities, social justice for consumers, fairness for food system workers, and ecological considerations for interdependent systems (Agyeman et al., 2002; Allen, 2004; Webber \& Dollahite, 2008). Thus, sustainable agriculture research has focused on topics like soil health (Doran \& Zeiss, 2000), climate change (Lal, 2004), economic viability of small farms (Ikerd, Devino, \& Traiyongwanich, 1996), human health (Horrigan, Lawrence, \& Walker, 2002), justice and equity (Agyeman, Bullard, \& Evans, 2002; Allen, 2010), and AFNs (Allen, 2004; Feenstra, 2002; Hinrichs, 2000).

The challenge of both movements continues to be where these ideals can intersect to create a sustainable situation in which disparate needs of producers and consumers can be met. Low-income consumers may be interested in fresh, healthy, local produce, but may experience food access issues related to limited flexibility in food budgets (Bruce \& Som Castellano, 2017; Byker, Shanks, Misyak, \& Serrano, 2012; Webber \& Dollahite, 2008), availability of food items (Kaiser, Carr, \& Fontanella, 2017), inconsistent transportation (Bruce \& Som Castellano, 2017; Di Noia, Monica, Cullen, \& Thompson, 2017), and inconvenience (Bruce \&
Som Castellano, 2017) while farmers need to consider production scalability of their land, products, and market potential (Webber \& Dollahite, 2008). In addition, Webber \& Dollahite's (2008) research underscored the importance of relationship-building that is needed and/or desired between producers and consumers, which of course takes time and effort for both groups.

Food hubs are one form of AFNs that connect small, local producers and neighborhood consumers (Berti \& Mulligan, 2016). Engagement and meaningful connections between producers and consumers are important in terms of differentiating localized markets from conventional markets (Berti \& Mulligan, 2016, Perrett \& Jackson, 2015). Values that underscore successful food hubs include transparency, democracy, equity, and access (Berti \& Mulligan, 2016). Transparency allows for the modes of production, quality, and traceability of food to be shared with consumers. Democracy places the control of the supply chain into the hands of the small producers. Equity generates fair income for the small-scale producers, concurrently offers food at reasonable prices for the consumer, and extends accessibility to low-income populations. Access is about getting the food to consumers in an organized way that maintains a short supply chain (Berti \& Mulligan, 2016).

Online ordering platforms have the ability to reach those who live in food deserts or are foodinsecure by eliminating physical access and transportation issues to securing food. This could help achieve an AFN goal of reaching marginalized populations. An online system also has the potential to connect consumers with a greater number of local producers because the aggregation, marketing, and distribution of food are an organized effort.

\section{Methods}

This research was part of a larger collaborative project funded through Ohio State University (OSU), a public land-grant university, and included faculty from OSU, the private Methodist Theological School in Ohio (MTSO), Seminary Hill Farm at MTSO, Franklinton Farms nonprofit urban farm, and the Ohio Cooperative Development Center, which facilitates the Ohio and West Virginia Food 
Hub Network. Our research reflects the shared values of the group's partners: the desire to bring together sustainable agriculture with CFS. The unique partnership brought together localized knowledge about food access and food production to explore the viability of an online food hub that could serve areas with low food access and provide new markets for local producers.

The research team sought perspectives from both residents living in the extremely impoverished Franklinton neighborhood in Columbus, Ohio, and small-scale Ohio producers; participants were selected by using established connections of the project partners. We adopted a pragmatic approach (Vannini, 2008) to investigate how producers and consumers each think about the possible challenges and opportunities of engaging with a local online food hub. The qualitative methods used were driven by the research questions and chosen to enhance existing knowledge (Nowell \& Albrecht, 2018; Tashakkori \& Teddlie, 2010) on food hubs, CFS, and sustainable agriculture. Research questions were defined utilizing the CFS framework, as well as the knowledge and questions that emerged from the collaborative group. Semistructured producer interviews, consumer focus groups, and consumer demographic surveys were used to gain a more complete picture of the opportunities and challenges of a locally sourced online food hub. When interacting with participants, the research team emphasized the preliminary nature of this research and that, though we sought to understand the viability of a food hub, the pilot of this project was not guaranteed.

\section{Data Collection Procedures}

Producers. Fifteen small-scale producers within 150 miles $(241 \mathrm{~km})$ of Columbus, Ohio, were identified through previously established relationships with Seminary Hill Farm and MTSO. Family farms that grossed under US $\$ 350,000$ in annual sales were identified as small-scale farms (Burns, 2018). Eight of these 15 producers were recruited to participate in a semistructured interview with two trained researchers. Researchers contacted producers via phone to gauge interest in participating in the study, and the principal farmer or the person who was most engaged in the management and de- cision-making of the farm's production was recruited to participate. In many cases, this person was the farm owner. If the producer agreed to participate, the research team members travelled to the producer's farm to conduct the interview. Each interview lasted at least 30 minutes.

After arriving at the farm, the lead research team member reviewed the study's aims again and reviewed the consent form with the producer. The lead researcher conducted the interview, taking minimal notes, while the other researcher took notes on the entire interview in as much detail as possible. Producer interviews were not tape-recorded in an effort to create an optimal setting for producers to feel comfortable enough to fully participate in the interview process. Producers were asked questions related to their willingness to engage in a possible online food hub, the type of products they might be interested in growing for this new market, pricing of those products, level of experience with wholesale markets, logistical opportunities and challenges with the proposed market, and any current third-party certifications. The semistructured interview design gave researchers the ability to ask open-ended and follow-up questions as needed to gather a sufficient level of detail from producers.

Immediately following each interview, the two research team members debriefed together to ensure the most objective understanding of the producers' responses. Within 24 hours, each team member documented her interview notes on a commonly shared online portal for other team members to review. Detailed records of all personal and methodological notes were also documented to account for decisions, inferences, and interpretations related to data collection, analysis, and study procedures.

Consumers. Residents of the lower-income neighborhood of Franklinton in Columbus, Ohio, were recruited via informational flyers and word-ofmouth to participate in focus groups. The focus groups were held at the neighborhood public library in the evening on different days of the week. Participants were allowed to bring children, and food was provided. Twenty-one residents participated, spanning three focus groups, each of which 
lasted 90 minutes. As an incentive, each participant received a US $\$ 20$ gift card to a local supermarket. A licensed court stenographer provided live transcription, which was later sent to researchers for analysis.

After consenting to participate, focus group members were first asked to fill out a 30-item survey, which documented demographic information, food security measures, and household food access methods. The lead research team member then facilitated a discussion prompting input about an online ordering system developed to improve food access within their community. Focus group members were asked questions related to their current food access, food-related values that may affect their decision-making, participation in AFNs, interest in online food ordering, interest in local food, and current neighborhood communication mechanisms.

\section{Data Analysis Procedures}

The research team engaged in inductive analysis to identify themes that emerged from the producer interviews and the consumer focus groups using structural and data-driven coding processes (DeCuir-Gunby, Marshall, \& McCulloch, 2011). Three researchers, two of whom led the focus groups and interviews, reviewed interview notes and focus group transcripts. Each researcher independently coded data for general themes and discussed those themes with members of the research team, reconciling any differences and discussing interpretations (DeCuir-Gunby et al., 2011; Padgett, 2008). The researchers then discussed the interviews and transcripts in the context of the original values and frameworks of sustainable agriculture and CFS, revising code names to create a theorydriven codebook (DeCuir-Gunby et al., 2011). The qualitative methodological rigor used for the study is considered both dependable and trustworthy, which is akin to validity and reliability in quantitative studies (Franklin \& Ballan, 2011). Language used to identify the key themes presented in this paper reflect the words used by participants during interviews and focus groups. The research team then identified quotes to use as supporting evidence. Surveys were analyzed using descriptive statistical analysis in SPSS.

\section{Results}

\section{Producers}

Producer Characteristics. Small-scale Ohio producers interviewed for this project had established relationships with Seminary Hill Farm and MTSO and were located within a 150 -mile $(241-\mathrm{km})$ radius of Columbus, Ohio. Most of the farms were primarily operated by the farm owners with occasional hired support. In line with MTSO's commitment to environmental sustainability, these producers employed a variety of sustainable agriculture practices, including minimizing chemical inputs, using non-GMO seed and animal feed, raising livestock on pasture, and diversifying production. One producer had organic certification through the USDA, although others described their farms as using organic practices.

Of the 15 small-scale producers identified, researchers conducted semistructured interviews with eight. Producers were less available to participate in the research process because interviews were conducted in late spring and early summer, a very busy time for growers. The eight producers interviewed offer an array of products, including fruits, vegetables, eggs, chicken, turkey, pork, beef, lamb, canned and pickled produce, honey, condiments, and sauces. While all had diversified production strategies, five mainly produced pastured meat, two focused on fruits, vegetables, and eggs, and one sold fruits, vegetables, and value-added products.

One farm has organic certification through the USDA. The others described their products as grass-fed, pastured, non-GMO, and/or sustainably grown and relied on their customers to "selfcertify" them by visiting the farm or establishing a relationship with the farmer. All producers had experience with wholesale marketing beyond selling to MTSO, including selling to restaurants, boutique shops, butcher shops, and other small universities. Six of the eight also marketed their products directly to consumers through on-site sales, farmers markets, or CSAs. While several farms sold to restaurants and customers in the town in which they were located, Columbus is the primary customer base for the majority of farms. 
Producer themes. We identified three primary themes in our interviews with the producers: willingness to participate, price guarantees and order reliability, and economic viability of farm business. These three themes are representative of the opportunities and challenges producers identified with participating in a food hub serving a low-income food insecure community.

Willingness to participate. Producers expressed interest in participating in a food hub to provide access to a new market to sell their products, which could support farm expansion. Several producers (P) expressed excitement and willingness to produce new products, citing the ability to earn money with statements like, "If I know I can sell it, I will find a way to produce it" (P9). While six of the producers already marketed their products directly to consumers, the food hub was an opportunity to increase community sales without the need for farmers to lead marketing efforts. Producers wanted to provide quality food to the local community and saw participation in the food hub as a feasible way to do this. "[The farm would] know we're getting good food out to people, which is our ultimate goal" (P6).

Some producers valued the proposed food hub because it would target distribution in a low-income, food-insecure community and improve food access. However, concerns with this model were also expressed due to the premium prices of the local products. Producers valued "feeding [their] neighbors" (P13) and were excited about the food hub project as a new outlet for their products to build the local food system in Ohio. One producer creatively considered how his farm might provide highquality ground beef at a lower cost for the food hub. Some producers suggested using education about buying local and cooking classes as ways to "create more sustainable relationships with our food" (P6). "Hopefully, the overall scheme will be a new food system for Central Ohio. That's the dream" (P4).

Price Guarantees and Order Reliability. A second theme that developed consistently in interviews with producers was the need for price guarantees and order reliability. When considering participation in a new market such as a food hub, producers wanted a guarantee that the market was viable. $\mathrm{P} 6$ and $\mathrm{P} 9$ mentioned that they would want a two- to three-year contract to guarantee consistent orders. Expanding production for a new market such as a food hub requires planning, investment, and risk. Producers consistently stated a need for one-year notice for large wholesale orders to plan for the birth and growth of livestock and seasonal rotation of vegetable crops. Farmers needed to know in advance when and how much of their products would be needed. Start-up costs for expansion to meet food hub orders were suggested as a barrier for producers, with two specifically stating they would need help with these startup costs in the amount of several thousand dollars. P6 stated, "Small producers cannot cover all costs upfront," while P9 said, "Capital outlay is fairly intensive for a food hub."

Producers also explained the need for up-front deposits for large wholesale orders. They noted that the initial outlay of cost and risk could be offset by consistent orders and payments. One producer, in particular, cited his experience working with Seminary Hill Farm as a game changer in the way he does business. After receiving up-front deposits for regular orders from Seminary Hill Farm, this producer went to his other wholesale customers-a butcher shop and restaurants—and asked for deposits. This helped stabilize his business. Farmers need a guarantee of consistent, reliable consumers to make their participation in a food hub economically possible.

\section{Economic Viability of Farm Business. Every} producer interviewed emphasized the need for their participation in a food hub to support the overall sustainability and economic viability of their farm business. P10 expressed this concern, saying "Is this going to be something where producers make money or a labor of love?" Though producers wanted to participate in this type of food market and were excited to offer their products to a new customer base, they needed to be able to make a profit and make a living through their farm sales. P8 commented, "My kids need to eat all year," while P9 reiterated, "I know that I'm not going to get rich with this, but I need to make a living - I need to pay the bills."

Producers raised concerns about how selling in 
a low-income neighborhood and collaboration with other farmers would affect the economic viability of the food hub. Specifically, producers recognized that their local products sell at a premium price, which low-income individuals may not be able to afford and/or may not choose to purchase when similar items are available for lower prices at a grocery store. P3 stated, "Marketing to that area would be difficult for us," and P13 described the predicament by saying, "I wish I could say we could slash our prices, but with farmers' margins so low..." Additionally, some producers shared frustrations that they encountered accepting government assistance payments such as the Supplemental Nutrition Assistance Program (SNAP) and the Special Supplemental Nutrition Assistance Program for Women, Infants, and Children (WIC). Producers stated that payments took too long to process and were not desirable, best represented by P3: "I can't stuff coupons in my gas tank to get home."

Table 1. Consumer Demographics

\begin{tabular}{|c|c|c|}
\hline Variable & $\begin{array}{c}\text { Number } \\
(N=21)\end{array}$ & $\%$ \\
\hline \multicolumn{3}{|l|}{ Gender } \\
\hline Female & 15 & $71.4 \%$ \\
\hline Male & 6 & $28.6 \%$ \\
\hline \multicolumn{3}{|l|}{ Race } \\
\hline White/Caucasian & 15 & $71.4 \%$ \\
\hline Black/African American & 4 & $19.1 \%$ \\
\hline More than one race & 2 & $9.5 \%$ \\
\hline \multicolumn{3}{|l|}{ Education Level } \\
\hline Less than high school & 3 & $14.3 \%$ \\
\hline High school graduate or GED & 6 & $28.6 \%$ \\
\hline Some college or 2-year degree & 5 & $23.8 \%$ \\
\hline Undergraduate degree & 3 & $14.3 \%$ \\
\hline Graduate or professional degree & 2 & $9.5 \%$ \\
\hline Did not respond & 2 & $9.5 \%$ \\
\hline \multicolumn{3}{|l|}{ Annual Income (US\$) } \\
\hline$<\$ 15,000$ & 8 & $38.1 \%$ \\
\hline$\$ 15,000-24,999$ & 3 & $14.3 \%$ \\
\hline$\$ 25,000-49,999$ & 1 & $4.8 \%$ \\
\hline$\$ 50,000-74,999$ & 2 & $9.5 \%$ \\
\hline$\$ 75,000-99,999$ & 1 & $4.8 \%$ \\
\hline$\$ 100,000+$ & 1 & $4.8 \%$ \\
\hline Did Not Respond & 5 & $23.8 \%$ \\
\hline \multicolumn{3}{|l|}{ Food Security Status } \\
\hline Food secure & 9 & $42.9 \%$ \\
\hline Food insecure & 12 & $57.1 \%$ \\
\hline \multicolumn{3}{|l|}{ SNAP Assistance } \\
\hline Yes & 6 & $28.6 \%$ \\
\hline No & 15 & $71.4 \%$ \\
\hline
\end{tabular}

Producers also expressed concern that a food hub may create competition and comparison among producers, making the project less profitable for individual producers because the orders received by each would be too small to be economically beneficial. Producers also expressed concerns about marketing their products in aggregate with other farms because they have different standards for their products (e.g., grass-fed vs. grass-finished) and rely on quality differentiation as a marketing strategy. Additionally, logistical concerns about food safety and shared liability when marketing in aggregate through a food hub came up as concerns. P3 asked, "Whose neck is on the line with food safety?" Pricing and marketing concerns derive from the larger concern and theme that producers need to make a living from their farms and that participation in a food hub requires consideration of the overall economic viability of the farm business.

\section{Consumers}

Consumer characteristics. Focus group participants completed a self-administered demographic survey. Results are presented in Table 1. Twenty-one $(N=21)$ consumers participated in the three focus groups. The average age of the participants was 43 $(S D=13.56)$, and the average household included three members. Participants had lived in the neighborhood for an average of 16.63 years $(S D=17.43)$. Several lived in the neighborhood most of their lives or had returned to the neighborhood after living away for a period of time. The majority of participants were women $(71.4 \%)$. Most participants identified themselves as White/Caucasian (71.4\%), followed by Black/African American (19.1\%). Nearly $48 \%$ had some college education, and $52.4 \%$ of participants had an annual income less than US $\$ 24,999$. The majority $(57.1 \%)$ were food-insecure using the USDA-six item scale, and $28.6 \%$ participated in SNAP during the previous year. Participants were asked to consider how their household makes food purchasing decisions. Specifically, they were asked to 
consider the importance of food quality, price, taste, and whether it was local or organic. A majority of participants $(80 \%)$ identified price as a concern, which was the most important consideration among both food-secure and food-insecure participants. Fewer than half the participants $(40 \%)$ considered whether food was locally grown when making a purchase. Those who were food-insecure considered locally grown food at a higher rate $(58.3 \%)$ than those who were food-secure $(12.5 \%)$.

Consumer themes. We identified three salient themes from the consumer focus groups: price point, transparency and trust, and communication. Within-group analysis, when comparisons are made by the researcher within focus groups, and between-group analysis, when comparisons are made among focus groups, were employed to extract the three identified themes from the data. Each focus group transcript was analyzed on its own to identify themes within the group. Themes that were present in all groups were then analyzed across the groups to determine which three themes were the most salient.

Price point. The most prominent concept that was raised by consumers was price. Consumer $(\mathrm{C})$ participants referenced favorable aspects of the proposed online food hub; however, their desire to use an online food hub was contingent upon price point. For example, participants spoke about the appeal of the convenience of an online food hub, stating it would save them time that they would typically spend traveling to and from the grocery store, but that the convenience had to be affordable for them to utilize the proposed online platform:

Just the online, you know, is easier than the traveling, you know, type deal, you know, because right now I have my license, but I don't have a car. Cost a lot of money right now. So, getting my produce now and then waiting until I get cab fare to go get the rest is pretty cool. Depending on how much it is. (C14)

While consumers expressed interest in supporting local producers by using the online food hub, it was only to the extent that the price of product and fees was affordable for them. Four consumers energetically shared their perspectives. C27 stated, "I love to support local, so getting it from central Obio is cool as long as the price isn't too high." C29 agreed, stating, "That's probably the bottom line: The price." The focus group leader asked, "So what do you think would make you choose a locally produced item over another one?" C21 stated, "Pricing. A lot of it is pricing."

Consumers' concern about price encompasses the price of products, service fees, delivery charges, and ability to use SNAP or WIC for products or delivery. Several times the consumers inquired about delivery fees and shared their experiences with supermarket delivery fees. C13 asked, "What is going to be the delivery charge? Is it worth it for them to deliver it for that price, or for you to just go into the store and do it yourself? That's what you have to really look at." C14 shared, "That's a big deal for me," noting other stores' required minimum purchase for free delivery and the hidden fees associated with online ordering. The importance of price is further evident in an exchange between group members and the interviewer when the interviewer attempted to explore what else the consumers found important when choosing what food to buy. When asked about "other things that are important," C13 simply said, "Coupons," and C20 added, "That would be nice if the farmers market took coupons." Although the consumers did not articulate price as the only important factor, coupons are closely related and were generally desired.

Transparency and trust. A second prominent theme among the focus groups is the desire for transparency and trust of an online food hub. Although consumers mentioned various favorable aspects of an online platform, such as convenience and supporting local producers, being able to trust the producers who grow and supply the product to the food hub was a concern verbalized by several consumers. C19 stated, "Yeah, I mean, because who's running the business, too? They could feed you anything. Seriously." Concerns related to trust evoked somewhat strong objections to the idea of an online platform. Consumers discussed how they like to physically touch the food they purchase to determine its quality. "I suppose if you had to, I'd have to do 
it, but I still prefer going to a farmers market and seeing what I'm buying" (C11). They also like to shop for their own food in person, so they can read ingredients and determine if the product meets their dietary needs or preference, including whether it is organic, non-GMO, or meets other dietary preferences.

Skepticism about online portrayal of products was evident. Consumers questioned what would keep an online platform from advertising a higher quality product than what was delivered to them. For example, if they ordered fruit online, they claimed it could be bruised or overripe when they picked it up or it was delivered.

"A lot of people like to see their produce rather than, you know, seeing it on a screen. You want to touch it. I mean, if it's yours, you know you're buying it, I guess. See that the bananas are nice and ripe." (C14)

Trust regarding the delivery method was vocalized as well. Participants questioned if the vehicle delivering the product would have proper refrigeration.

Knowing where and how the food is grown was also important to consumers, including the amount of time it takes the product to make it from harvest to delivery. C20 stated, "I just want to see how it gets from point $A$ to point B. That's it. If you can show me how that $T$-bone steak came from this spot and came to me, I'd buy it in a heartbeat." C7, whose word choices indicate some level of knowledge about growing produce, shared the need for more information about the use of chemicals on plants and how producers were caring for animals: "There is a need for] Best care practices. Like, how do you treat your cows? How do you treat your plants? What are you spraying your plants with?"

Communication. The third theme observed among consumer focus groups is communication, in terms of participants sharing news, events, and programs. Consumers voiced that they are often unaware of things happening in the neighborhood and mentioned word of mouth and flyers delivered to households as favorable ways to communicate information in the neighborhood. C13 shared:
"I pass it on when I hear it to different people, because with the flyer today, I told my neighbor upstairs, next door, one down the street. It was up to them to come, but I try to pass it on as I get it... A lot of times it's just the people that you're around and you hear a conversation about it, you know."

\section{C14 added:}

"I had a lady who I rode the bus with, and she's not from here, but she's been living here for the past 10 years or so, and she said, 'honey, you got to know people in Columbus to find out something.' I say, 'yes, you do."”

C13 agreed, stating, "Or certain things you will never know."

\section{Discussion}

Our research provided the opportunity to learn from the perspectives of small-scale producers and consumers who live in a low-income and low-food access neighborhood as they relate to the potential development of an online food hub. We identified themes from interviews and focus groups and then considered these themes in the context of common frameworks of sustainable agriculture and CFS. Allen (2004) describes the purpose of an AFN as a way sustainable agriculture and CFS align to support farm and food security. The research team continues to consider how producer and consumer perspectives can help determine the best strategies to leverage resources to meet our desire of bringing together sustainable agriculture and CFS values and whether these ideals can be actualized in the region where this project took place. Following, we provide an analysis of the themes that were presented to better understand where potential intersections occur between sustainable agriculture and CFS.

\section{Producers}

When MTSO, Seminary Hill Farm, and Franklinton Farms initiated this project, there was an assumption that an online food hub as an AFN would be a win-win for small-scale farmers and residents in the Franklinton neighborhood. While producers we interviewed were interested in sup- 
porting low-income consumers in areas where local, fresh, and healthy food options were limited, their primary need related to ensuring the economic viability of their business, which is one component of sustainable agriculture. This was evident through the producers' statements about needing price guarantees and reliable orders. In addition, many expressed a need for creative strategies to retain appropriate pricing for their products, noting that the pricing would not likely be low enough for food-insecure and low-income consumers. Guthman et al.'s (2006) review of CSAs and farmers markets showed similar interest in wanting to address food insecurity and make food more available to low-income consumers, but the bottom line must be considered. Small-scale farms, such as those working with MTSO and Seminary Hill Farm, face challenges to maintaining the viability of their farm business. Producers' sentiments about wanting to provide food to low-income consumers but feeling challenged by their own need to have fair prices for their high-quality products exemplify the intersection of CFS and sustainable agriculture framings, both of which consider social justice and equity as underlying values. When designing this project, we included Seminary Hill Farm and Franklinton Farms in the planning and research process, but we did not have for-profit farms directly involved until the interviewing process. If we had included their voices earlier on, we might have recognized that while the for-profit small-scale farms in our study may share similar values as the Seminary Hill Farm and Franklinton Farms, their mechanism for meeting their financial needs is different than that of nonprofit or higher education institutional-based farms. For-profit farms are influenced more by the market system embedded in a local, regional, national, and international industrialized food system, while Seminary Hill Farm and Franklinton Farms are able to receive grants and foundation support to help subsidize their efforts to provide high quality, organic, local food to their customers. Franklinton Farms, specifically, is able to provide a sliding scale of prices through their farm stand and CSA program in the low-income neighborhood where the study took place because it is a 501(c)(3) and can access certain resources unavailable to for-profit entities. Producers were frustrated by the reality they faced trying to meet the needs of consumers unable to pay the price for their products. When we think about the sustainable agriculture and CFS values of justice, equity, and fairness, we must consider how we make the system work for all involved when the needs seem to be in opposition to one another. If we had brought one or more of the for-profit farms to the table, our assumptions may have been challenged, or we may have asked ourselves, "Justice and equity for whom? Who decides?"

Since beginning our study, a large volume of research and reliable information has emerged about the economic viability of food hubs, with variations existing within and between localities, states, and regions (e.g., Matson, Thayer, \& Shaw, 2016; Rysin \& Dunning, 2016). We held a conference at MTSO in November 2018 to share our research, but it is evident that small-scale producers in our study that are not currently connected to others through this aggregation method could benefit from resource-sharing about food hubs. This could include working with national and regional food hub networks (e.g., Ohio and West Virginia Food Hub Network, Michigan Food Hub Learning and Innovation Network, the National Good Food Network's Food Hub Center) that exist to support peer producers by providing education, reaching non-academic audiences through accessible research, helping work through challenges experienced by food hub members, and bridging any divergences between academics studying food hubs and practitioners implementing them (Levkoe et al., 2018; Wallace Center, 2013).

Direct-to-consumer programs that allow the use of SNAP, WIC, and Senior Farmers Market Nutrition Program coupons, and double-up SNAP programs are intended to provide low-income consumers with opportunities to purchase healthy and fresh food, while also providing producers with potentially new customers and subsidies to bridge the gap between the value of the produce being sold and what the customer is able to pay. Some producers in our study shared negative experiences from participating in government programs because payments were often delayed. Guthman et al.'s (2004) study identified similar concerns about any extra time needed to market produce and par- 
ticipate in programs like SNAP, although it seemed to be less risky for larger-scale farmers markets or farms with established revenue streams and was easier for nonprofits that could access diversified funding. Community partners working with smallscale farms or food hub networks may be a way to help educate producers about how these programs fit within AFN frameworks with CFS and sustainable agriculture values, as well as provide technical assistance to troubleshoot any challenges they have with government procedures, equipment, or reimbursement processes.

Producers expressed uncertainty about the risks and time, beyond economic aspects, that would be involved with a potential online food hub. Producers noted the amount of time needed to participate in an online food hub in new markets, especially if it meant expanding their operation. The sentiment was expressed that food movements (i.e., food messages in the mass media) constantly shift, and there would be a need to ensure that the supply and demand were in balance. Producers also expressed concerns about any extra time for marketing, as most of them felt limited in their availability to add more to their workload. It is important to consider how community partners like those in this project from private and public higher-education institutions and nonprofit groups might support producers in these endeavors by incorporating for-profit stakeholders into projects, sharing responsibilities for marketing materials, and in the event producers do not have time, serving as liaisons to advocacy groups, food policy councils, and government entities who might support systemic changes representative of sustainable agriculture and CFS values.

In our study, producers expressed a desire and need for a cultural shift in Central Ohio. The smallscale producers in our study met a specific set of requirements in order to provide food for MTSO, aligning with production methods that do not use chemicals and consider stewardship of natural resources in the cultivation of healthy soil as part of MTSO's commitment to ecotheology and sustainability. Producers felt that the food hub project itself may need some additional educational components in order for consumers to understand more about how food is grown, how prices are determined, how to reduce food waste, and how consumer food purchases ultimately can create greater demand for an improved sustainable regional food system in which people are more connected to the land and farmers.

Many producers in our study described the need to provide low-income consumers with education about the potential benefits of local and organic food and farming practices. It is unclear whether this was due to producers' beliefs about low-income consumers lacking adequate information, having limited access to information, or having conflicting or untrustworthy information that could inform and promote purchasing behaviors favoring local and/or organic food (Wunderlich, Gatto, \& Smoller, 2018). While it is beyond the scope of this article to discuss the wide range of research regarding the purported health and environmental benefits of local and organic food, and what even constitutes "local" or "organic" food in the first place (Allen \& Hinrichs, 2007; Schnell, 2013), we know consumers from all socioeconomic backgrounds are exposed to food marketing messages that can sometimes be considered valueladen, confusing, politically motivated, and contradictory (Allen \& Hinrichs, 2007; Kareklas, Carlson, \& Muehling, 2014; Nestle, 2007; Wunderlich et al., 2018).

Low-income consumers are exposed to mass media food marketing and targeted healthy food messaging to those at high risk for chronic diet-related diseases, but often have to weigh other considerations about food purchasing, such as the availability, affordability, and accessibility of local and/or organic food options (Rodman, Palmer, Zachary, Hopkins, \& Surkan, 2014). Byker, Rose, and Serrano (2010) recommend the use of several education and outreach "demand-side strategies" that are based on their study of participants who followed a local food diet. They describe the need for a variety of messaging that is for subgroups of people with different demographic characteristics that could be potential customers (e.g., seniors, immigrants). Education strategies include providing information about "food handling and proper storage," encouraging involvement by multiple family members during meal preparation, incorporating information about "balanced meals using seasonal 
products" in local food guides, and shifting cultural views on local food to describe it as a normal standard of consumption, not an "alternative" way of eating (Byker et al., 2010, p. 134). Other outreach activities suggested include "neighborhood canning parties," potlucks, sharing family recipes through local media sources, encouraging "one-day or one-week local food diet challenges," and having more food-based celebrations in communities (Byker et al., 2010, p. 134).

Future research could focus on having low-income consumers identify where they have learned about local and/or organic food, analyzing food marketing messages provided by local, state, and federal AFN programs, and analyzing the sources and the quality of sources of food messaging targeted to low-income consumers or those living in low-income communities. These efforts could inform how a food hub might include producer-suggested educational components that would be effective, impactful, and informative.

Producers in this study were interested in hearing consumers' perspectives as a way to bridge their gaps in understanding, since most did not have relationships with low-income communities and markets. Producers valued learning about how low-income consumers made their decisions around food, in addition to consumers' interest in purchasing local foods. Producers were proud of the quality of their food and want a way to showcase this food to their low-income neighbors, if there could be ways to overcome the risks and barriers to marketing, pricing, and food access. Their concerns beg the question about who bears responsibility for ensuring healthy food access, especially for producers interested in creating AFNs that incorporate the ideals of sustainable agriculture and CFS.

\section{Consumers}

Price, transparency and trust, and communication were the three prominent themes that emerged from our consumer focus groups. These themes reflect those of transparency, democracy, equity, and access that Berti and Mulligan (2016) identify as necessary to foster connections between producers and consumers and uphold the alternativeness of local food systems. We unexpectedly recognized that the interviews with small-scale producers, the focus groups conducted with residents, and the research team meetings between all groups involved were important aspects of building relationships and using inclusive processes that themselves build transparency and trust, which are important goals of local food movements (Allen, 2010) and underscore CFS practices (Pothukuchi et al., 2002; Winne, 2004). As the team moves forward and considers the feasibility of an online food hub, including producers and consumers in other processes will be important. This may include having producers come to the neighborhood for a farm day event in coordination with Franklinton Farms or finding ways for residents to meet and/or visit local producers as a way to build trust for food products and address any assumptions producers have about residents' interest or needs.

Overall, focus group participants, who were overwhelmingly food-insecure, desire high-quality food at an affordable price. CFS strategies intend to address the need for improved access to quality, healthy foods, recognizing that price is a common barrier (Pothukuchi et al., 2002; Winne, 2004). AFNs operate as market-based endeavors, and small-scale producers have little room to negotiate prices. While producers expressed the need to educate consumers about their products and how pricing is determined, the same issue exists in regards to communicating that low-income consumers have a set amount each month to spend on food. Despite the CFS ideals of economic and social justice for all people within the food system (Hamm \& Bellows, 2002), most households were concerned about their own family's financial well-being. It was clear that prices for food through the proposed online food hub would need to be similar to what they pay at supermarkets and other food retailers where they shop.

Consumers desired high-quality produce and expressed their trust of certain supermarkets where they shopped, although many shared that they would buy more fresh items if there were markets available in the neighborhood. While some wanted very specific transparency in regard to pinpointing their food source, others preferred to not have access to that information. Interestingly, some focus group conversations moved back and forth be- 
tween the desire for food that had limited additives or for food that was grown without chemicals to statements about regularly eating frozen pizzas and fast food. We interpreted this to mean that a social bias may have occurred or that transparency had multiple meanings. Ideals of quality were related to either consistency and trust experienced with certain brands or stores or through handling foods directly and being able to see, smell, and touch the food items. Researchers have noted similar consumer concerns about food quality at farmers markets, such as rotten produce, presence of bugs, and uncertainty about where food was grown (Di Noia et al., 2017).

One theme that emerged, but was unexpected, among the consumer focus groups was a sense of camaraderie. The focus groups, in addition to serving as a chance for the researchers to learn from the consumers and for the consumers to share their thoughts about local food, served as a communal space to share conversation and information with fellow residents. Although the residents expressed their thoughts about local food and the possibility of an online food hub, they seemed to enjoy the company of other residents, some they had never met before. The presence of camaraderie and the meeting of neighbors in our study is an unexpected positive outcome and demonstrates that including residents in local food conversation can foster a sense of community (Allen, 2010) in addition to discussing food issues. Food hub viability research suggests the importance of community outreach and educational activities about the potential impacts of local food purchasing and how to use local ingredients (LeBlanc, Conner, McRae, \& Darby, 2013). However, small-scale producers in our study seem hard-pressed for time to lead these efforts. It is important to find community partners who are focused on complementary services that would support producers' efforts and would be recognized as trustworthy and welcoming organizations, agencies, or spaces by residents in those communities. In the community where the study took place, such partnerships have resulted in hosting cooking demonstrations at neighborhood events, using local ingredients donated from Franklinton Farms at free community meals and soup kitchens, providing cooking classes using ingredi- ents from Franklinton Farms and the neighborhood food pantry, bringing children to Franklinton Farms to learn about food, hosting free neighborhood festivals that incorporate local and organic food into the food that is served, and working with OSU to educate families with young children in the community about growing food, preparing meals, and celebrating together through shared meals. As we move forward, we recognize how important it is to pay attention to the community's modes of communication, as other AFN programs have suffered because of lack of awareness or advertising (Colasanti et al., 2010; Freedman et al., 2016).

\section{Meeting the Needs of Producers and Consumers}

We hypothesized that producers would be oriented toward the economic viability of their small-scale operations and that consumers would be oriented toward improved food access that was convenient and affordable. Our findings suggest confirmation of these sentiments, but the underlying values of producers and consumers are imperfect and intersect along sustainable agriculture and CFS frameworks. Both groups were interested in supporting their community, although there were realistic challenges expressed in terms of logistics like price, delivery, and scale. Consumers did not seem to have a strong sense of what products could be produced or available locally, and producers seemed to have limited experience or knowledge about low-income consumers. Using a CFS framework would require a greater effort by producers, consumers, and the research team to build relationships; Feenstra (2002) refers to this as developing social spaces where people can come together to communicate with one another and build capital. Similar to Hinrichs' (2000) findings, producers and consumers must consider different needs and priorities related to prices and costs with AFNs that focus on relationships.

While producers favored organic and sustainable farming practices, this was not of high interest to consumers. It is unclear if there is an educational gap about what organic means, as expressed by some producers, or if it is the perception of organic and/or local food as more expensive and unattainable. Consumers discussed food more in terms of safety, which is an important aspect of 
CFS strategies that focus on environmental and public health (Winne, 2004). This is where messaging is important. Producers also described the potential for this project to launch others and change the food system. In order for AFNs to fulfill their purpose, Hoey and Sponseller (2018) stated that independent food projects will need to spark the emergence of other independent food projects, and the collective presence of these food projects will bring about structural change to the food system.

Consideration has been given to how to appropriately scale-up AFNs to be more impactful and to counteract the harmful effects of the unsustainable, conventional food system. Scaling up must be done appropriately and at a pace that does not detract the authenticity and underlying values of AFNs (Berti \& Mulligan, 2016); otherwise, AFNs risk furthering injustice and inequity, the antithesis of CFS and sustainable agriculture values. Berti and Mulligan (2016) identify three main challenges that need to be met when scaling up: (1) Not compromising quality for consumers by providing a consistent and appropriate quantity of food; (2) Making available a variety of products; and (3) Making healthy and fresh food accessible and convenient to consumers, with regard for low-income populations.

\section{Conclusion}

Our project explored scaling up the AFN presence in a low-income neighborhood by seeking input from producers and consumers on the feasibility of an online food hub. We were able to identify the presence of values associated with sustainable agriculture and CFS. The information and insight provided by the producers and consumers was invaluable in determining that an online food hub is something that appealed to some producers and consumers for several reasons, but also that overall the barriers identified by both producers and consumers were more prominent than the benefits, and the desire for the proposed online food hub was not sufficient to move forward with a full-scale online food hub at the time. Had the producers and consumers not been involved in our process of exploration, it could have been assumed that simply by creating an online food system available to a predominately low-income neighborhood, jus- tice would have been served, when in reality this is not the case. Low-income individuals often are not aware of things happening in their own neighborhoods, as evidenced by the communication consumer theme we identified. Therefore, specific outreach to this population when considering alternative food projects is indispensable. On the other hand, small-scale producers must keep in mind the ability for their farming businesses to be financially stable and sustainable, so more planning is needed to ensure the economic feasibility of an online food hub. Without the considerations for consumers and producers, food scholars and activists will continue, while likely unintentionally, to perpetuate the injustices they seek to eliminate within our food system.

\section{Addendum}

In early March 2020, Ohio businesses began shutting down due to the COVID-19 pandemic. This included the farmers market where Franklinton Farms sold produce weekly. Within 24 hours of notification of the closure, the nonprofit farm team determined that the financial loss of the closed market and the potential loss of crops ready to harvest for consumers would be devastating without shifting to an alternative model to stay in business, as they were also in between CSA seasons and CSA revenue. On April 28, 2020, the research team spoke with Rebecca Brown, one of the co-executive directors, for an update. The farm created an online ordering system using the Square platform, worked with a volunteer living in the area where the market was generally held to host a curbside pick-up on her porch, and created a similar curbside pick-up system of orders in the Franklinton neighborhood at one of their rehabbed farm houses. The farmers market then developed a spreadsheet of farmers and ways to order their food and created a curbside pick-up at a community center. Franklinton Farms is maintaining orders for both locations, accepts SNAP, Produce Perks, and discounts its produce for people living in their low-income community. At this time, it has doubled its distribution income for the same time last year, with 50 households from Franklinton and 350 customers outside of Franklinton purchasing food. Most of the advertising has been through so- 
cial media and emails to people who have participated with Franklinton Farms. The online ordering system allows for people to pay for others' produce, which is the third highest grossing item. Franklinton Farms works with a local pantry and distributes the produce to low-income individuals each week.

Franklinton Farms has also worked with three individuals (two live in the community, one works there) to provide additional items for sale through its site (including sustainably harvested ramps, jams, flowers), with non-Franklinton Farms producers receiving $70 \%$ of the sales. Rebecca expressed a willingness to work with other producers in the community, as long as they are able to provide $50 \%-75 \%$ off their product. They are hoping to increase sales to persons using SNAP, but they had nine such customers in the third week of April 2020. While Rebecca was unsure of the level of need in the neighborhood, a different food pantry in the neighborhood is seeing an increased need, requesting donations so they can purchase three times as much product from the food bank.

Seminary Hill Farm launched an early-bird version of its CSA program through an online weekly ordering system, with customers able to choose items and pick up themselves at the farm on the campus of Methodist Theological School in Ohio. Other farmers in the study have participated in webinars and Zoom calls with the Ohio Ecological
Food and Farm Association, receiving support from their networks to build online platforms, troubleshoot issues, and understand legislation related to COVID-19. Many are part of two farmers markets in the area that are providing curbside pick-up through online pre-orders, and some are participating in a few local food distribution businesses. It is unknown what the impact of institutional and restaurant closures have had and will continue to have on the farms.

\section{Acknowledgments}

We are grateful for our team from the Methodist Theological School in Ohio, Seminary Hill Farm, Franklinton Farms, and Ohio State University, as well as the small-scale producers and Franklinton neighborhood residents who took time to participate in the project. Thanks to Kathy Dickson, Tim Van Meter, and Tadd Peterson (MTSO) and Kareem Usher (OSU) for assisting with interviews, focus groups, and research processes. During the development and execution our project, one of our team leaders and friends, Patrick Kaufman, who cofounded Franklinton Farms and worked for food justice through his role at MTSO, Franklinton Farms, and in the community, passed away from a brief battle of cancer before seeing his vision come to life and the completion of this project. This project is in loving memory of him.

\section{References}

Agriculture Act of 2014, Pub.L. 113-79. 128 Stat 649.

Agyeman, J., Bullard, R. D., \& Evans, B. (2002). Exploring the nexus: Bringing together sustainability, environmental justice and equity. Space \& Polity, 6(1), 77-90. https://doi.org/10.1080/13562570220137907

Alaimo, K., Briefel, R. R., Frongillo, Jr., E. A., \& Olson, C. M. (1998). Food insufficiency exists in the United States: Results from the third National Health and Nutritional Examination Survey (NHANES III). American Journal of Public Health, 88(3), 419-426. https://doi.org/10.2105/ajph.88.3.419

Allen, P. (2004). Together at the table. University Park: The Penn State University Press.

Allen, P. (2010). Realizing justice in local food systems. Cambridge Journal of Regions, Economy, and Society, 3(2), $295-308$. https://doi.org/10.1093/cjres/rsq015

Allen, P., \& Hinrichs, C.C. (2007). Buying into 'buy local': Engagements of United States local food initiatives. In D. Maye, L. Holloway, \& M. Kneafsey (Eds.), Alternative food geographies: Representation and practice (pp. 255-272). Oxford, UK: Elsevier Science.

Berti, G., \& Mulligan, C. (2016). Competitiveness of small farms and innovative food supply chains: The role of food hubs in creating sustainable regional and local food systems. Sustainability, 8(7), 616. https://doi.org/10.3390/su8070616

Bruce, A. B., \& Som Castellano, R. L. (2017). Labor and alternative food networks: Challenges for farmers and consumers. Renewable Agriculture and Food Systems, 32(5), 403-416. https://doi.org/10.1017/s174217051600034x 
Burns, C. (2018). Farm structure. Washington, D.C.: U.S. Department of Agriculture Economic Research Service. Retrieved from https://www.ers.usda.gov/topics/farm- economy/farm-structure-and-organization/farm-structure/

Byker, C., Rose, N., \& Serrano, E. (2010). The benefits, challenges, and strategies of adults following a local food diet. Journal of Agriculture, Food Systems, and Community Development, 1(1), 125-138. https://doi.org/10.5304/jafscd.2010.011.013

Byker, C., Shanks, J., Misyak, S., \& Serrano, E. (2012). Characterizing farmers' market shoppers: A literature review. Journal of Hunger \& Environmental Nutrition, 7(1), 38- 52. https:// doi.org/10.1080/19320248.2012.650074

Casey, P., Goolsby, S., Berkowitz, C., Frank, D., Cook, J., Cutts, D., . . Children's Sentinel Nutritional Assessment Program Study Group. (2004). Maternal depression, changing public assistance, food security, and child health status. Pediatrics, 113(2), 298-304. https://doi.org/10.1542/peds.113.2.298

Colasanti, K. J. A., Conner, D. S., \& Smalley, S. B. (2010). Understanding barriers to farmers' market patronage in Michigan: Perspectives from marginalized populations. Journal of Hunger \& Environmental Nutrition, 5(3), 316-338. https://doi.org/10.1080/19320248.2010.504097

Coleman-Jensen, A., Rabbitt, M. P., Gregory, C. A., \& Singh, A. (2018). Household food security in the United States in 2017 (Economic Research Report No. 256). Washington, D.C.: U.S. Department of Agriculture. Retrieved from https://www.ers.usda.gov/webdocs/publications/90023/err-256.pdf?v $=0$

Community Food Security Coalition. (n.d.). Community food security programs: What do they look like? Venice, CA: Community Food Security Coalition. Retrieved from http://foodsecurity.org/CFS projects.pdf

Cook, J. T., \& Frank, D. A. (2008). Food security, poverty, and human development in the United States. Annals of the New York Academy of Sciences, 1136(1), 193-209. https://doi.org/10.1196/annals.1425.001

DeCuir-Gunby, J. T., Marshall, P. L., \& McCulloch, A. W. (2011). Developing and using a codebook for the analysis of interview data: An example from a professional development research project. Field Methods, 23(2), $135-155$. https://doi.org/10.1177/1525822x10388468

Di Noia, J., Monica, D., Cullen, K. W., \& Thompson, D. (2017). Perceived influences on farmers' market use among urban, WIC-enrolled women. American Journal of Health Behavior, 41(5), 618-629. https://doi.org/10.5993/AJHB.41.5.11

Doran, J. W., \& Zeiss, M. R. (2000). Soil health and sustainability: Managing the biotic component of soil quality. Applied Soil Ecology, 15(1), 3-11. https://doi.org/10.1016/s0929-1393(00)00067-6

Feenstra, G. (2002). Creating space for sustainable food systems: Lessons from the field. Agriculture and Human Values, 19, 99-106. https://doi.org/10.1023/a:1016095421310

Franklin, C., \& Ballan, M. (2011). Reliability and validity in qualitative research. In B. A. Thyer (Ed.), The handbook of social work research methods (2nd ed.) (pp. 273-292). Los Angeles: Sage.

Freedman, D. A., Vaudrin, N., Schneider, C., Trapl, E., Ohri-Vachaspati, P., Taggart, M., .. . Flocke, S. (2016). Systematic review of factors influencing farmers' market use overall and among low-income populations. Journal of the Academy of Nutrition and Dietetics, 116(7), 1136-1155. https://doi.org/10.1016/j.jand.2016.02.010

Gundersen, C., \& Ziliak, J. P. (2015). Food insecurity and health outcomes. Health Affairs, 34(11), 1830-1839. https://doi.org/10.1377/hlthaff.2015.0645

Gundersen, C., Dewey, A., Crumbaugh, A. S., Keto, M., Engelhard, E., Odeen, B., . . Rayulangi, P. (2017). Map the meal gap 2017: Highlights of findings for overall and child food insecurity. Chicago: Feeding America. Retrieved from https://www.feedingamerica.org/sites/default/files/research/map-the-meal-gap/2015/2015-mapthemealgap-execsummary.pdf

Guthman, J., Morris, A. W., \& Allen, P. (2006). Squaring farm security and food security in two types of alternative food institutions. Rural Sociology, 71(4), 662-684. https://doi.org/10.1526/003601106781262034

Hamm, M. W., \& Bellows, A. C. (2003). Community food security and nutrition educators. Journal of Nutrition Education and Behavior, 35(1), 37-43. https://doi.org/10.1016/s1499-4046(06)60325-4

Hinrichs, C. C. (2000). Embeddedness and local food systems: Notes on two types of direct agricultural markets. Journal of Rural Studies, 16(3), 295-303. https://doi.org/10.1016/s0743-0167(99)00063-7 
Hoey, L., \& Sponseller, A. (2018). "It's hard to be strategic when your hair is on fire": Alternative food movement leaders' motivation and capacity to act. Agriculture and Human Values, 35(3), 595-609. https://doi.org/10.1007/s10460-018-9850-Z

Horrigan, L., Lawrence, R. S., \& Walker, P. (2002). How sustainable agriculture can address the environmental and human health harms of industrial agriculture. Environmental Health Perspectives, 110(5), 445-456. https://doi.org/10.1289/ehp.02110445

Ikerd, J., Devino, G., \& Traiyongwanich, S. (1996). Evaluating the sustainability of alternative farming systems: A case study. American Journal of Alternative Agriculture, 11(1), 25-29. https://doi.org/10.1017/s088918930000669x

Kaiser, M. L., Carr, J., \& Fontanella, S. (2017). A tale of two food environments: Differences in food availability and food shopping behaviors between food insecure and food secure households. Journal of Hunger and Environmental Nutrition, 12(2), 1-21. https://doi.org/10.1080/19320248.2017.1407723

Kareklas, I., Carlson, J. R., \& Muehling, D. D. (2014). "I eat organic for my benefit and yours": Egoistic and altruistic considerations for purchasing organic food and their implications for advertising strategies. Journal of Advertising, 43(1), 18-32. https://doi.org/10.1080/00913367.2013.799450

Lal, R. (2004). Soil carbon sequestration impacts on global climate change and food security. Science, 304(5677), 15231627. https://doi.org/10.1126/science.1097396

Larson, N. I., Story, M. T., \& Nelson, M. C. (2009). Neighborhood environments: Disparities in access to healthy food in the U.S. American Journal of Preventive Medicine, 36(1), 74-81.E10.https://doi.org/10.1016/i.amepre.2008.09.025

LeBlanc, J. R., Conner, D., McRae, G., \& Darby, H. Building resilience in nonprofit food hubs. Journal of Agriculture, Food Systems, and Community Development, 4(3), 1-15. https://doi.org/10.5304/jafscd.2014.043.005

Levkoe, C. Z., Hammelman, C., Craven, L., Dandy, G., Farbam, J., Harrison, J., \& Mount, P. (2018). Building sustainable food systems through food hubs: Practitioner and academic perspectives. Journal of Agriculture, Food Systems, and Community Development, 8(2), 107-122. https://doi.org/10.5304/jafscd.2018.082.008

Martin, M. S., Maddocks, E., Chen, Y., Gilman, S. E., \& Colman, I. (2016). Food insecurity and mental illness: Disproportionate impacts in the context of perceived stress and social isolation. Public Health, 132, 86-91. https://doi.org/10.1016/j.puhe.2015.11.014

Matson, J., Thayer, J., \& Shaw, J. (2016). Running a food hub: Assessing financial viability. (USDA Rural Development Service Report No. 77, Vol. 3). Retrieved from https://www.rd.usda.gov/files/publications/SR\%2077\%20FoodHubs\%20Vol3.pdf

Nestle, M. (2007). Food politics: How the food industry influences nutrition, and health (Revised and expanded edition). Berkeley: University of California Press.

Nowell, B., \& Albrecht, K. (2018). A reviewer's guide to qualitative rigor. Journal of Public Administration Research and Theory, 29(2), 1-16. https://doi.org/10.1093/jopart/muy052

Olson, C. M. (1999). Nutrition and health outcomes associated with food insecurity and hunger. The Journal of Nutrition, 129(2), 512S-524S. https://doi.org/10.1093/jn/129.2.521s

Padgett, D. K. (2008). Data analysis and interpretation. In D. K. Padgett (Ed.), Qualitative methods in social work research (2nd ed.) (pp. 131-178). Thousand Oaks, CA: Sage.

Perrett, A., \& Jackson, C. (2015). Local food, food democracy, and food hubs. Journal of Agriculture, Food Systems, and Community Development, 6(1), 7-18. https://doi.org/10.5304/jafscd.2015.061.003

Pothukuchi, K., Joseph, H., Burton, H., \& Fisher, A. (2002). What's cooking in your food system? A guide to community food assessment. Edited by K. Siedenburg \& K. Pothukuchi. Venice, CA: Community Food Security Coalition. Retrieved from the IssueLab website: https://www.issuelab.org/resources/2905/2905.pdf

Raja, S., Ma, C., \& Yadav, P. (2008). Beyond food deserts: Measuring and mapping racial disparities in neighborhood food environments. Journal of Planning Education and Research, 27, 469-482. https://doi.org/10.1177/0739456x08317461

Rodman, S. O., Palmer, A. M., Zachary, D. A., Hopkins, L. C., \& Surkan, P. J. (2014). “They just say organic food is healthier": Perceptions of healthy food among supermarket shoppers in Southwest Baltimore. Culture, Agriculture, and Food Environment, 36(2), 83-92. https://doi.org/10.1111/cuag.12036 
Rysin, O., \& Dunning, R. (2016). Economic viability of a food hub business: Assessment of annual operational expenses and revenues. Journal of Agriculture, Food Systems, and Community Development, 6(4), 7-20. https://doi.org/10.5304/jafscd.2016.064.002

Sarmiento, E. R. (2017). Synergies in alternative food network research: Embodiment, diverse economies, and more-than-human food geographies. Agriculture and Human V alues, 34(2), 485-497. https://doi.org/10.1007/s10460-016-9753-9

Schell, S. M. (2013). Food miles, local eating, and community supported agriculture: Putting local food in its place. Agriculture and Human V alues, 30, 615-628. https://doi.org/10.1007/s10460-013-9436-8

Sustainable Agriculture Research and Education. (2012). Sustainable agriculture grants. College Park: University of Maryland. Retrieved from https://www.sare.org/Grants

Tashakkori, A., \& Teddlie, C. (2010). Sage handbook of mixed methods in social \& behavioral research (2nd ed.). Los Angeles, California: Sage.

U.S. Department of Agriculture (USDA) National Agricultural Library (NAL). (n.d.). Sustainable agriculture education and training director. Beltsville, MD: National Agricultural Library. Retrieved from https://www.nal.usda.gov/afsic/edtr/sustainable-agriculture-education-directory

USDA National Institute of Food and Agriculture (NIFA). (2017). Community food projects [CFP] competitive grants program. Washington, DC: USDA NIFA. Retrieved from https://nifa.usda.gov/funding-opportunity/community-food-projects-cfp-competitive-grants-program

USDA NIFA. (2018). Food insecurity nutrition incentive [FINI] grant program. Washington, DC: USDA NIFA. Retrieved from https://nifa.usda.gov/program/food-insecurity-nutrition-incentive-fini-grant-program

Vannini, P. (2008). Critical pragmatism. In L. M. Given [Ed.] The Sage encyclopedia of qualitative research methods (pp. 161-63). Thousand Oaks, California: Sage.

Ver Ploeg, M., Breneman, V., Farrigan, T., Hamrick, K., Hopkins, D., Kaufman, P., ... Kim, S. (2009). Access to affordable and nutritious food: Measuring and understanding food deserts and their consequences. Report to Congress. Washington, DC: USDA Economic Research Service. Retrieved from https://www.ers.usda.gov/webdocs/publications/42711/12716 ap036 1 .pdf

Wallace Center. (n.d.). Food hub collaboration. Wallace Center at Winrock International. Retrieved August 2019 from https://www.wallacecenter.org/foodhubcollaboration

Webber, C. B., \& Dollahite, J. S. (2008). Attitudes and behaviors of low-income food heads of households toward sustainable food systems concepts. Journal of Hunger and Environmental Nutrition, 3(2/3), 187-205. https://doi.org/10.1080/19320240802243266

Weinfeld, N. S., Mills, G., Borger, C., Gearing, M., Macaluso, T., Montaquilia, J., \& Zedlewski, S. (2014). Hunger in America 2014: National report prepared for Feeding America. Rockville, Maryland: Westat and The Urban Institute. Retrieved from http://help.feedingamerica.org/HungerInAmerica/hunger-in-america-2014-full-report.pdf

Winne, M. (2004). Community food security: Promoting food security and building healthy food systems. Washington, DC: Congressional Hunger Center. Retrieved from https://www.hungercenter.org/wp-content/uploads/2011/07/Community-Food-Security- Mark-Winne.pdf

Wunderlich, S., Gatto, K., \& Smoller, M. (2018). Consumer knowledge about food production systems and their purchasing behaviors. Environment, Development and Sustainability, 20, 2871-2881. https://doi.org/10.1007/s10668-017-0021-y

Zenk, S. N., Schulz, A. J., Israel, B. A., James, S. A., Bao, S., \& Wilson, M. L. (2005). Neighborhood racial composition, neighborhood poverty, and the spatial accessibility of supermarkets in metropolitan Detroit. American Journal of Public Health, 95(4), 660- 667. https://doi.org/10.2105/ajph.2004.042150 